\title{
The Effects of Perceived Leadership Styles and Organizational Citizenship Behaviour on Employee Engagement: The Mediating Role of Conflict Management
}

\author{
Ahmad Zairy Mohd Soieb ${ }^{1}$, Jamilah Othman ${ }^{2} \&$ Jeffrey Lawrence D'Silva ${ }^{1}$ \\ ${ }^{1}$ Institute for Social Science Studies, Universiti Putra Malaysia, Malaysia \\ ${ }^{2}$ Faculty of Educational Studies, Universiti Putra Malaysia, Malaysia \\ Correspondence: Jeffrey Lawrence D'Silva, Institute for Social Science Studies, Universiti Putra Malaysia, \\ Malaysia. Tel: 60-3-8947-1862. E-mail: jld@putra.upm.edu.my
}

Received: February 8, $2013 \quad$ Accepted: March 10, 2013 Online Published: March 22, 2013
doi:10.5539/ijbm.v8n8p91
URL: http://dx.doi.org/10.5539/ijbm.v8n8p91

\begin{abstract}
In recent years, employee engagement has become a topic that keeps coming up and often debated by the top management particularly in the public sector agencies due to the differences in the work and leadership styles, commitment and job performances exhibited by the new officers that seem to generate mix perceptions and, to some extent, disrupt the good relationship between them and senior officers thus destabilizing the organizations. Although this scenario is particularly known to occur in the public sector, adequate research on employee engagement that is heavily influenced by the styles of leadership and organizational citizenship behavior are poorly executed. Meanwhile, conflict management which is believed to mediate the relationship is also misunderstood based on the resulting gap in Social Exchange Theory and Path Goal Theory. This review is part of a growing body of research on employee engagement and it is believed that it will contribute vastly to future research on similar topics.
\end{abstract}

Keywords: leadership, employee engagement, conflict management, organizational citizenship behavior

\section{Introduction}

The concept of employee engagement is rapidly gaining recognition, discussion regarding its usage as a measurement for comparisons and importance in the workplace (Ferguson, 2010; Kular, Gatenby, Rees, Soane and Truss, 2008; Little and Little, 2006). In most of the previous researches, engagement is proven to have some characteristics similar to other constructs such as commitment and stickiness (Benest, 2008) in organizational behavior, but distinct from other constructs such as appointment and obligation in certain context especially in social event (Macey and Schneider, 2008; Vazirani, 2007), involvement of the self and organizational citizenship behavior (Dickinson, 2009). An engaged employee is proven to have high level of commitment which influences others to increase the productivity of the work in order to improve the image of the organization and escalating the profits (Devi, 2009).

Nevertheless, organizational commitment could be distinguished from engagement as the formerbehaviour is appertained to a person's positive reactionand feeling attach towards the organization (Vance, 2006) whereas organizational citizenship behavior (OCB) involves informal and voluntary behaviors that can help the subordinates and other levels of workersthus improve the cooperation in the organization (Saks, 2006). Based on researches, organizations knew that topmanagement and midriff officers were the key drivers in antiquity of engagement in the manpower (Tomlinson, 2010). In telling to that, Hockey and Ley (2010) have specifically identified that to heighten the level of employee engagement, effective leadership has been acknowledged as an essential prerequisite and even demonstrate possible link to organization performance (Townsend and Gebhardt, 2008). Specifically, based in the literature with highly confirming results, among the leadership styles, the association of employee engagement and transformational leadership increase the level ofemployee engagement (Ghafoor, Qureshi, Khan and Hijazi, 2011). Even so, different generational groups of workers have different work characteristics and preferred different styles of leadership (Yu and Miller, 2005) which arouse motivation and contribution to the organizational achievement (Graham, 1995). An engaged workforce also means less conflict. It is believed that by communicating and mediating with employees, conflict could possiblybe dealt 
with effectively and constructively (Mills, 2011). Furthermore, there is some anecdotal evidence to suggest that in times of conflict, individuals generally behave in pro-social ways where employees are tend to engage in OCB thus increases employee engagement (Karam, 2011).

\section{Employee Engagement}

Engagement is a strong bond between oneself and the job responsibility where people fully express themselves physically, cognitively and emotionally at work (Wildermuth, 2008). And although the term of employee engagement was originated from a study of morale way back in 1920s, but the concept was only positioned out clearly by Kahn in 1990 (Tiwari, 2011) and finally, later established by the Gallup Organization (Little and Little, 2006). There are many different definitions of employee engagement used by the researchers and at some point of time, situations or contexts, the definition and usage of employee engagement has become in the state of confusion (Welch, 2011), especially when relating the subject to certain situations in different environments or involving other predictors or in relationships with other variables. For example, in 2009, a behavioral survey has reported that, in one single organization, there were twenty different employee engagement models. As for that, the term could be used differently depending on the scope and concept of the research and yet, still confining to the basic and general perspective of employee engagement (Robinson, Perryman and Hayday, 2004).

According to Kahn (1990), employee engagement is a multi dimensional construct in that employees could be involved emotionally, cognitively and physically. Some researchers believed that burnout was simply the opposite of employee engagement as it consisted of energy, involvement and efficacy that was embedded the role of the employees. More recent researcheshave substantiated the notion that employee engagement is a valid and reliable concept (Hassan and Ahmed, 2011). (According to Kahn, employee work is a multi dimensional build in that employees could be emotionally, cognitively and physically meshed. Some scholars believed that employee involution was just the opposite of burnout as it consisted of liveliness, wonder and effectualness that employee brought to their persona. Writer recent investigate has substantiated the whim that employee meshing is a logical and sure construct (Hassan and Ahmed, 2011).

From academic overview, there are four (4) major approaches defined the existing form of employee engagement: (a) Need-Satisfying Approach by Kahn in 1990, (b) Burnout-Antithesis Approach by Maslach et al. in 2001, (c) Satisfaction-Engagement Approach by Harter et al. in 2002, and (d) Multidimensional Approach by Saks in 2006 (Shuck, 2011). Coincidently, there are also four (4) models of employee engagement used by organizations which are The Gebauer Attraction, Retention and Engagement Model by Gebauer in 2008, The Towers Perrin Model by Perrin in 2003, The Structural Equation Model of Engagement by Langford, Parkes and Metcalf in 2006 and The High Performance Model by Vance in 2006 (Muller, 2009). These four (4) approaches and models have been debated and tried to lay out the significant dimensions and conditions which the differences, disagreements and direct-oppositeness among them that have finally came to an agreement. Actually, the approaches prepare the platform for the process of the engagement to take place and the models prioritize the areas for improvement based on their potential impact on engagement (Aon Hewitt, 2011). In addition to that, most of the researchers have tried to correlate factors which lead to employee engagement and developed models which could bring out the best solution for top management to deal with the existing employees and the new intakes. Their analyze targets to determine the factors or drivers that will increase the level of employee engagement (Markos and Sridevi, 2010). Robinson, Perryman and Hayday (2004) have shown that committed employees perform better, however, the strongest driver is a sense of feeling valued and involved especially in decision making (Perrin, 2003). In term of the organizations and managerial levels, exceptional leadership (Wellins, Bernthal and Phelps, 2011), good reputations as employers and care a great deal about customer satisfaction contributed to the ascending level of employee engagement (Perrin, 2003).

There are also three (3) dimensions of engagement construct such as cognitive (Shuck and Herd, 2012) or psychological (Ferguson, 2010; Ghafooret al., 2011; Shuck, 2011) engagement which involves meaningfulness, safety and availability as predictors (Saks, 2006); emotional engagement which involves belief, willingness and investment (Shuck and Herd, 2012) and behavioral engagement (Ram and Prabhakar, 2011; Shuck and Herd, 2012) which involves discretionary effort (Shuck and Herd, 2012). Based on a study in 2004, it was found that in the aspect of psychological conditions, such as meaningfulness, safety and availability, those conditions were positively and significantly related to employee engagement. And from these three (3) conditions, meaningfulness was proven to have the highest influentialcorrelationtowards employee engagement.

The construction of the employee engagement concept is also structured on some other basis such as the demarcation between the definitions of employee engagement and other similar constructs. In recent years, several constructs namely job engagement and organization engagement (Kular, Gatenby, Rees, Soane and Truss, 
2008), job satisfaction (Choo, 2009), organizational commitment, organizational citizenship behavior (Robinson, Perryman and Hayday, 2004) and job involvement (Little and Little, 2006), have mistakenly identified as the antecedents of employee engagement. Among those constructs, organizational commitment and organizational citizenship behavior were repeatedly reported as can be used interchangeably with the engagement term in some of the contextual studies. But later in 2008, organizational commitment was finally determined as a vital parameter for an assessment of employee engagement in an organization. From the outcome of the investigation, it is concluded that the increase of organizational commitment level affected positively job performance as well as the effectiveness of the organization hence reduced unpunctuality, absenteeism as well as employee turnover (Mohapatra and Sharma, 2010). The differences between employee engagement and organizational commitment have finally resolved as the latter, through evident, has a psychological link between the employee and the organization which makes it less likely that the employee will voluntarily leave the organization (Matin, Jandaghi, Karimi and Hamidizadeh, 2010). Recent researches also indicate that OCB is the important predictor of employee engagement. OCB is anassertive actionrecognized within workplaces that exhibitsthe characteristics through taking innovative initiatives proactively in finding favorable circumstancesto contribute to the utmost possible capacity and to perform somewhat above and beyond the employment contract. Notwithstanding, this construct comprehending the bigger factorof employee engagement and it cannot act as a replacement for engagement impartially (Markos and Sridevi, 2010).

The important thing to be highlighted here is that the concept of employee engagement has been evolving since the past twenty years (Mohapatra and Sharma, 2010; Shuck and Herd, 2012). And as for that, every aspect of employee engagement, especially, in relation with other constructs such as leadership styles, organizational citizenship behavior, employee commitment (Drake, Blake and Swallow 2009) and work-life balance (Wildermuth and Pauken, 2008), should be, from time to time, explored and tested as different variables (independent, dependent, moderating or mediating).

\section{Underlying Theories}

Social Exchange Theory (SET) which was initiated by Hormans in 1958 (Devan, 2006), implies that social behavior is the result of an exchange process. The main reason of this exchange is to maximize benefits and minimize costs. In accordance with this theory, people measure the potential benefits and risks of social relationships. People will tend to terminate or disregard the relationship when the risks outbalance the rewards (Cherry, 2010). This theory includes a number of important assumptions such as; firstly, individuals are generally rational and constantly obligated in estimatingthe cost and benefits in social exchanges; secondly, those who are engaged in interactions are rationally exploring certain ways to escalate the profits or benefits that could be acquired from those situations, especially in terms of complying withthe basic needs of an individual; thirdly, exchange processes that generatevarious forms of advantage such as rewards for individuals and certain benefits in the organizations, lead to the reshaping of social interactions especially in the workplaces; and lastly, individuals are divided into two categories, that are,mission-oriented and profit-oriented in an unboundsocial system which is highly competitive. Because of the competitive nature of social systems, exchange processes lead to separation of power and privilege in a group of people who interact regularly and in a relatively same manner. Whereas power in social exchange belongs to those individuals who possess greater possessions that provide an advantage in the social exchange thus hold better position to benefit from the exchange.

Theorists have also proposed that SET is likely capable of providing insight regarding how transformational leaders influence organizational outcomes. SET suggests that employees reciprocate leaders' behavior towards them with their own matched behaviors on a pro quo (mutual reciprocity) basis as part of a social exchange relationship development process. Social exchange relationships between leaders and their subordinates develop from interactions between these parties and are motivated by the mutual benefits derived from the exchanges (Hansen, 2010).

The main and general assumption of Leadership Theories is that the top management by exercising their power, charismatic style, credibilityor authority can either easily instruct orinspirethe skillful workers to increase the organizational performance. When dealing with the effects of leaders on their workers, most of the researchershave the inclination focusing on the leaders' attitudes and their common behaviors. The study was also assumed that the followers have the same perceptions towards the leaders and behaved in quite the same pattern when they were requested to complete some tasks.On the other hand, the leaders also enactedsimilarly towards the workers or the workers were administered the same approaches in order toachieve the mission of the organizations (Ilies, Nahrgang and Morgeson, 2007).

In the reformulated version of Path-Goal Theory (PGT) by House and Mitchell (1974) and House (1996), has 
advanced two general propositions where they concluded that leader behavior is a source of motivation and satisfaction to the subordinates. In addition to that, it created a healthy environment in supporting the effective performance. The theory was formulated to elucidatethe methods that were used by the leaders to advocate and support the subordinates in accomplishing the mission of the organization which they have agreed uponin consideration of creating the smooth and clear direction without any obstacles in attaining the goal of the organization. In most of the time, leaders will facilitate their workers by eliminating any obstacles such as conflict, nihilism and hindrance, from other party which prevent them from expediting the process of actualizing the visions of top management with significant increment of monetary or non-monetary incentives occasionally.

Related to SET, PGT similarly explaining about the positive behaviors of employees from a diverse workgroups, when both parties obey and agree to the exchange rules, the result will be a more convincing with loyal relationship and mutual commitments. For that reason, the workers who are more engaged have the potential of being more trustful individuals and maintain greater quality in their relationships with their superior and, consequently,believed toexhibit more positive attitudes and aspirations toward the organization (Ram and Prabhakar, 2011).

The theories aren't universal to explain everything regarding the magnitude of the relationships between leaders and followers, and citizenship behavior of the subordinates when dealing with conflict at the workplace or in the organizations. Basically, people aren't always autonomous and self-contained and most of the times demonstrate altruism and altruistic behaviors. Not everybody estimate their verbal and physical reactions towards other people in terms of cost and rewards. And generally, when it comes to making decisions, people are not always being rational. Though SET and PGT have established the fundamental scope of employee behaviors that predicted the wholesome relationship, influence and motivational elements provided by the leaders in order to build up healthy working environments, yet the aspect of handling problems or resolving conflict which finally leads to higher productivity and organization performances, is not clearly stated. In managing the conflict especially among intergenerational officers (Hutchings and McGuire, 2006), the leaders must identify and communicate (Ruddick, 2009) the appropriate strategies in bridging the differences (Dovidio, Saguy and Shnabel, 2009) and improve the level of employee engagement (Stroud, 2009).

Chronologically, from past researches, the concept of employee engagement has naturally evolved on high involvement, empowerment, job motivation, organizational commitment and trust. Within the public sector there is a growing understanding of the fundamental of engagement as a catalyzeagent for driving high productivity and contentment in public servants (MacLeod and Clarke, 2009). And even some researchers had argued that, in some ways, all of these concepts are variations of the same fundamental issue, such as employee motivation and behavior.

\section{Employee Engagement and Leadership Styles}

In several researches, there are two conditions which projected employee engagement as having negative and positive association with the employees' perception of leadership styles in his or her immediate supervisors.Employee engagement is perceived as subsuming negative outcome from the employees when the supervisors are adopting classical or transactional leadership styles. Whereas when the leaders are embracing visionary and organic leadership, employee engagement is regarded as having positive association with the employees' perception. These different perceptions are actually caused by embedded apprehension that the traditional type of leadership styles is only suitable for certain age and generations. Nevertheless, theseemployee characteristics seems to moderate the relationship between perceived leadership styles and employee engagement in different ways. Regarding need for achievement, when the employees' score on this variable is higher, the stronger the positive association is between perceived visionary or organic leadership styles and employee engagement and the weaker the negative association is between employee engagement and classical or transactional leadership. By contrast, the higher equity sensitivity, the positive association between visionary or organic leadership and employee engagement tends to get weaker and the negative association between perceived classical or transactional leadership styles and employee engagement turns to get stronger. Finally, the higher employees' need for clarity is, the negative association found between perceptions of classical or transactional leadership and employee engagement tends to become weaker, whereas where employees' need for clarity is high, the positive association between visionary or organic leadership styles and employee engagement is weakened (Zhang, 2011). Consequently, while research around employee engagement is emerging and several models suggest leadership as a crucial element in the development of employee engagement, there remains a gap in understanding what leadership behaviors could affect engagement-encouraging cultures as well as the processes around which leader behaviors bring about higher levels of engagement (Shuck and Herd, 2012). 


\section{Employee Engagement and Organizational Citizenship Behaviour (OCB)}

OCB leads to employee engagement as it focuses on employee involvement and secures their commitment which definitely lies outside the prescribed parameters of any organization. Furthermore, Rukkhum (2010) supported the statement by proving that there was a positive relationship between employee engagement and OCB. From seven dimensions of $\mathrm{OCB}$, the most strongly co-relates with employee engagement is taking initiatives individually which means going an extra-mile (Mansoor, Aslam, Javad and Ashraf, 2012). While OCB involves voluntary and informal behaviors that can help co-workers and the organization, the focus of engagement is one's formal role performance also and not only extrarole and voluntary behavior. Engagement should be positively related to OCB, because employees who are engaged in their job should not only accomplish their formal role requirements, but should put forth extra effort to perform other activities that extend beyond their formal role requirements (Rana and Chhabra, 2011).

Previous study also suggests that a thorough understanding of OCB antecedents must account for the influence of potential contextual moderators (Dierdorff, Rubin and Bachrach, 2010) and mediators such as justice (Niehoff and Moorman, 1993), perceived organizational instrumentality and perceived individual instrumentality (Jiao, Richards and Zhang, 2010), effect the relationship between leadership and OCB or other constructs on OCB. Multiple studies have shown that different workforce cultures may view their relationships with OCB differently where in the study by Yu and Miller (2005), different workforce was referred to different generations.

\section{Employee Engagement and Conflict Management}

Every organization has conflict. The common thread is the insidious impact workplace conflict has on employee engagement, morale and productivity (Schnurman, 2011). Some disagreements among a diverse workforce that transition into conflict are problematic especially when different generations, gender or level of workers use their own styles to solve the conflict. If the members of the organization would like to function effectively at any level, not only within the organization, they must acquire conflict management skills.Practice of effective leadership inevitably requires a specific interpersonal skill especially in the areas of problem solving in conflict management, motivation, communication, and effective listening (DasGupta, 2011). This notion is supported by Trudel and Reio Jr. (2011)who stated that employees who effectively managingthe conflict,particularly during the latent phase (phase 1) and just before the triggering accident phase (phase 2),thus perceived as more skilled in communication and better suited for leadership roles.

With the increasing number of women (Brewer, Mitchell and Weber, 2002) and Gen Y (Chaudhuri and Ghosh, 2012; Sheahan, 2005) moving into decision making positions and intermix the patterns and levels of engagement in the organizations, the conflict management skill has became one of the main influential element on effective leadership styles.

\section{Conflict Management as Mediating Factor}

The achievement and stability of an organization depends on the ability of conflict recognition and the competency of managers in managing conflict at workplaces (Doherty, 2008). Conflict management indicates synthesis of all factors which can contribute to conflict resolution such as problem-solving discussions (Fisher, 2005) or its prevention. The factors involved are such as the betterment of communication, practicing several aspects in moral and spiritual disciplines in order to abandon any non-virtuous action and in addition to having in mind the life phases of parties included. Basically there are several approaches to conflict management. Apart from five (5) typical approaches and strategies on conflict management (Goldwich, 2006; Roark and Wilkinson, 1979), it is also important to highlight that the organization itself, which is also comprises of certain critical elements which interact with each other in order to achieve themission, actedas the third force in conflict. The organization materializes as the mediator between adversaries or as arbitrator. The most critical element in this third force is the managers who wisely used their experience to creatively evolve the existing strategies and objectives in resolving the conflict invariably. Moreover, it is generally ratified that conflict enacts as the most relentless test of leaders' interpersonal skills (Turkalj, Fosic and Dujak, 2008).

\section{The Nature of Mediating Factor}

Although employee engagement is believed could halt certain phasesin conflict, it does not mean that the behavior could eliminate conflict completely. This is because, despite the level of employee engagement is at the highest point, the smallest fraction of conflict still occurs but without affecting the adherence in workers of culturally diverse backgrounds. Therefore, it can be said clearly that disengaged employees are more likely to have some extent of controversy with their superiors and an engaged workforce means less conflict. In most situations, by mediating with employees and effectively communicating with them, it is attainable to deal with 
that conflict positively and constructively. A natural partner for employee engagement,for that reason, is positive conflict management, but not many studies have explored the role mediation has in this. By encompassing these two crucial areas, conflict management and employee engagement, organizations can generatean excellent circle of wellbeing, motivation, productivity and success (Mills, 2011).

If the public sector is to retain existing talented and committed officers and meet ever increasing expectations of organizational performance (Lacy, 2009) and at the same time facingthe conflict which at any time can escalate to crisis in the workplace, it has to take employee engagement seriously.

\section{Conclusion}

Several literature reviews have revealed that employee engagement has been conceptualized in many different ways. There is no single definition can comply with all situations and research has shown that employee engagement is modified and adapted in different form depending on the contexts of study. However, for this study, employee engagement, as a multi-faceted construct, is closely defined as according to Vazirani $(2007, p .2)$ who describe it as the level of involvement and commitment an employee has towards the organization and its value. As there are diverse conceptualizations of employee engagement, this makes the state of knowledge around employee engagement difficult to establish, as each piece of research is undertaken under a different context, syntax, semantics and synchronization, using different measures of engagement under different circumstances. This study suggests that employee engagement is a consequential construct that is clearly commendable of future research. One area in need of investigation is the predictors of engagement in different generations.

The theoretical gap and later the research framework which based on Social Exchange Theory (SET) and Path-Goal Theory (PGT) was explained by the relationship between perceived leadership styles and organizational citizenship behavior on employee engagement. The framework also includes conflict management as the mediating variable which predicted to expedite the process of engaging the employees or even increase the level of employee engagement. Most of the evidences of research suggest that these predictors can only influence one of these conditions at a time, thus need the virtuous research to uncover predictors which affect engagement as a whole.

\section{References}

Aon Hewitt. (2011). Trends in global employee engagement. Consulting talent and organization. Retrieved from www.aonhewitt.com

Benest, F. (2008). Retaining and growing talent: strategies to create organizational stickiness. PM magazine, ICMA public management, California, USA.

Brewer, N., Mitchell, P., \& Weber, N. (2002). Gender role, organizational status and conflict management styles. The international journal of conflict management. Flinders University of South Australia, Australia. http://dx.doi.org/10.1108/eb022868

Caldwell, B., \& Dake, D. (2009). Cultural context. Iowa state university, USA.

Chaudhuri, S., \& Ghosh, R. (2012). Reverse mentoring: a social exchange tool for keeping the boomers engaged and millennials committed. Human resource development review. USA: SAGE publications.

Cherry, K. (2010). What is social exchange theory? Psychology.

Choo, L. S. (2009). Factors that influence employee engagement: a study of Celestica Malaysia. Universiti Utara Malaysia.

Cingoz-Ulu, B., \& Lalonde, R. N. (2007). The role of culture and relational context in interpersonal conflict: Do Turks and Canadians use different conflict management strategies? International journal of intercultural relations. York university, Canada.

DasGupta, P. (2011). Literature review: e-leadership. Emerging Leadership Journeys. Regent University, USA.

Devan, J. (2006). Theories use in IS Research. Social exchange theory. York university, USA.

Devi, V. R. (2009). Employee engagement is a two-way street. Human resource management international digest. Emerald group publishing limited, Guntur Dt., India. http://dx.doi.org/10.1108/09670730910940186

Dickinson, L. (2009). An examination of the factors affecting organizational citizenship behavior. University of Tennessee, USA.

Dierdorff, E. C., Rubin, R. S., \& Bachrach, D. G. (2010). Role expectations as antecedents of citizenship and the 
moderating effects of work context. Journal or management. USA: SAGE publications.

Dionne, S. D., Yammarino, F. J., Atwater, L. E., \& Spangler, W. D. (2004). Transformational leadership and team performance. Journal of organizational change management, 17(2), 177-193. http://dx.doi.org/10.1108/09534810410530601

Doherty, N., \& Guyler, M. (2008). The essential guide to workplace mediation and conflict resolution: rebuilding working relationships. Kogan page limited, London, UK and Philadephia, USA.

Dovidio, J. F., Saguy, T., \& Shnabel, N. (2009). Cooperation and Conflict within Groups: Bridging Intragroup and Intergroup Processes. Journal of social issues, 65(2), 429-449. http://dx.doi.org/10.1111/j.1540-4560.2009.01607.x

Drake, J., Blake, J., \& Swallow, W. (2009). Employee engagement: the critical role of employee commitment. Education and training, 51(1), 23-42. http://dx.doi.org/10.1108/00400910910931814

Ferguson, A. (2010). Employee engagement: does it exist and if so, how does it relate to performance, other construct and individual differences? Macquarie University, Australia.

Fisher, R. J. (2005). Paving the way: contributions of interactive conflict resolution to peacemaking. Lexington books, USA.

Fox, S., \& Spector, P. E. (2008). Organizational Citizenship Behavior Checklist (OCB-C). Layola University Chicago, USA.

Ghafoor, A., Qureshi, T. M., Khan, M. A., \& Hijazi, S. T. (2011). Transformational leadership, employee engagement and performance: mediating effect of psychological ownership. African journal of business management. University of Central Punjabi, Pakistan.

Goldwich, D. (2006). The five approaches to resolving conflict. International quality and productivity centre. London, UK.

Graham, J. W. (1995). Leadership, moral development and citizenship behavior. Business ethics quarterly: ethics and leadership. Philosophy documentation centre, USA.

Hansen, S. D. (2010). Ethical leadership: A multifoci social exchange perspective. The journal of business inquiry. Washington university, USA.

Hassan, A., \& Ahmed, F. (2011). Authentic Leadership, Trust and Work Engagement. International Journal of Human and Social Sciences.

Hockey, J., \& Ley, I. (2010). Leading for engagement: how senior leaders engage their people. National school of government, UK.

Hopkins, W. G. (2008). Quantitative research design. Sportscience journal.sportsci.org. Auckland, New Zealand.

House, R. J. (1996). Path-goal theory of leadership: lessons, legacy and a reformulated theory. Leadership quarterly, 7(3), 323-352. http://dx.doi.org/10.1016/S1048-9843(96)90024-7

Hutchings, K., \& McGuire, D. (2006). Organization diversity and intergenerational conflict: human resource solution for achieving organization generation interaction. Academy of human resource development conference. Ohio, USA.

Ilies, R., Nahrgang, J. D., \& Morgeson, F. P. (2007). Leader-member exchange and citizenship behavior: a $\begin{array}{lllll}\text { meta-analysis. Journal of } & \text { applied }\end{array}$ http://dx.doi.org/10.1037/0021-9010.92.1.269

Jackson, D. V. (2011). Perception is reality: your strengths matter. Journal of leadership education. Liberty university, Georgia, USA.

Jiao, C., Richards, D. A., \& Zhang, K. (2010). Leadership and organizational citizenship behavior: OCB-specific meanings as mediators. Journal of business psychology. Springer, China.

Kahn, W. A. (1990). Psychological conditions of personal engagement and disengagement at work. Academy of Management Journal. http://dx.doi.org/10.2307/256287

Karam, C. M. (2011). Good organizational soldiers: conflict-related stress predicts citizenship behavior. $\begin{array}{llll}\text { International journal of conflict management, } & 22(3), & 300-319 .\end{array}$ http://dx.doi.org/10.1108/10444061111152982 
Kular, S., Gatenby, M., Rees, C., Soane, E., \& Truss, K. (2008). Employee engagement: a literature review. Working paper series no. 19. Kingston University, UK.

Lacy, J. C. (2009). Employee engagement: the development of a three dimensional model of engagement; and an exploration of its relationship with affective leader behaviours. School of management, Queensland University of Technology.

Little, B., \& Little, P. (2006). Employee engagement: conceptual issues. Journal of Organizational Culture, Communications and Conflict. Western Carolina university, USA.

Macey, W. H., \& Schneider, B. (2008). The Meaning of Employee Engagement. Industrial and Organizational Psychology, 1(1), 3-30. http://dx.doi.org/10.1111/j.1754-9434.2007.0002.x

MacLeod, D., \& Clarke, N. (2009). Engaging for success: enhancing performance through employee engagement. A report to government, UK.

Mani, V. (2011). Analysis of Employee Engagement and its Predictors. International Journal of Human Resource Studies, 1(2), 15-26. http://dx.doi.org/10.5296/ijhrs.v1i2.955

Mansoor, N., Aslam, H. D., Javad, T., \& Ashraf, F. (2012). Exploring Organizational Citizenship Behavior and its Critical Link to Employee Engagement for Effectual Human Resource Management in Organizations. Mediterranean Journal of Social Sciences.

Markos, S., \& Sridevi, M. S. (2010). Employee Engagement: The key to improving performance. International Journal of Business and Management. Canadian Centre of Science and Education, Canada.

Matin, H. Z., Jandaghi, G., Karimi, F. H., \& Hamidizadeh, A. (2010). Relationship between interpersonal communication skills and organizational commitment (case study: JahadKeshavarzi and University of Qom, Iran). European Journal of Social Sciences.

Mills, C. (2011). Optimising employee engagement and conflict management. Ark group and inside knowledge, UK.

Mohapatra, M., \& Sharma, B. R. (2010). Study of employee engagement and its predictors in an indian public sector undertaking. Global Business Review. New Delhi, India: Sage publications.

Niehoff, B. P., \& Moorman, R. H. (1993). Justice as a mediator of the relationship between method of monitoring and organizational citizenship behavior. The Academy of Management Journal, 36(3), 527-556. http://dx.doi.org/10.2307/256591

Perrin, T. (2010). Turbocharging employee engagement: the power of recognition from managers - part 1: the engagement engine.

Phillips, J., \& Edwards, L. (2009). Do you what kind of commitment they have? Managing talent retentionarticle. Retrieved from http://media.roiinstitute.net/pdf/Department-Retention-ESMjunjul10.pdf

Ram, P., \& Prabhakar, G. V. (2011). An enquiry into the mediatory role of employee engagement: evidence from the hotel industry in Jordan. Far East Journal of Psychology and Business, 5(2).

Rana, N., \& Chhabra, N. L. (2011). Employee engagement: a primer for strategic human resource management. Asian Journal of Research in Business Economics and Management. New Delhi, India.

Roark, A. E., \& Wilkison, L. (1979). Approaches to conflict management. Group and organization management journal, 4(4), 440-452. http://dx.doi.org/10.1177/105960117900400406

Robinson, D., Perryman, S., \& Hayday, S. (2004). The drives of employee engagement. Institut for employement studies, Birighton, UK.

Ruddick, G. E. (2009). Intergenerational leadership communication in the workplace. Clemson university, USA.

Rurkkhum, S. (2011). The Relationship between Employee Engagement and Organizational Citizenship Behavior in Thai Organizations. University of Minnesota, USA.

Saks, A. M. (2006). Antecedents and consequences of employee engagement. Journal of Managerial Psychology, 21(7), 600-619. http://dx.doi.org/10.1108/02683940610690169

Schnurman, M. (2011). How managers can resolve workplace conflicts effectively. Retrieved from http://www.nj.com/business/index.ssf/2011/11/resolving_workplace_conflicts.html

Sheahan, P. (2005). Generation Y: surviving (and thriving) with generation y at work. National library of Australia cataloging-in-publication data. Australia. 
Shuck, B. (2011). Integrative literature review: four emerging perspectives of employee engagement: an intergrative literature review. Human Resource Development Review, 10(3), 304-328. http://dx.doi.org/10.1177/1534484311410840

Shuck, B., \& Herd, A. M. (2012). Employee engagement and leadership: exploring the convergence of two frameworks and implications for leadership development in HRD. Human resource development review, 11(2), 156-181. http://dx.doi.org/10.1177/1534484312438211

Stroud, R. N. (2009). The relationship between leadership competence and employee engagement. The State University of New Jersey, USA.

Susaeta, L., Pin, J. R., Idrovo, S., Belizon, M. J., Espejo, A., Gallifa, A., Aguirre, M., \& Pedrozo, E. A. (2011). Generation of culture? Work attitude drivers: an analysis in Latin America and Iberian countries. University of Navarra, Barcelona, Spain.

Synodinos, N. E. (2003). The "art" of questionnaire construction: Some important considerations for $\begin{array}{lllll}\text { manufacturing studies. Integrated Manufacturing } & \text { Systems, } 14(3), \quad 237 .\end{array}$ http://dx.doi.org/10.1108/09576060310463172

The Scottish Government. (2007). Engagement in the Public Sector: A Review of Literature -Chapter 2: evolution and definition of employee engagement. Retrieved from http://www.scotland.gov.uk/Publications/2007/05/09111348/3

Tiwari, S. (2011). Employee engagement - the key to organizational success. Academy for professional excellence, Kolkata.

Tomlinson, G. (2010). Building a culture of high employee engagement. Strategic Human Resource Review, 25-31. Emerald group publishing limited, Weybridge, UK. http://dx.doi.org/10.1108/14754391011040046

Townsend, P., \& Gebhardt, J. (2008). Employee engagement - completely. Human resource management international digest. Emerald group publishing limited, USA. http://dx.doi.org/10.1108/09670730810869529

Trudel, J., \& Reio Jr., T. G. (2011). Managing workplace incivility: the role of conflict management styles-antecedent or antidote? Human Resource Development Quarterly. Wiley online library, USA.

Tulkarj, Z., Fosic, I., \& Dujak, D. (2008). Conflict management in organization. J. J. strossmayer university, Osijek, Croatia.

Vance, R. J. (2006). Employee engagement and commitment: A guide to understanding, measuring and increasing engagement in your organization. Society for Human Resource Management Article. SHRM foundation's effective practice guidelines, USA.

Vazirani, N. (2007). Employee engagement. Working paper series 05/07. College of management studies, Nerul, India.

Waters, J. (2010). Correlational research. Research Guidelines for Students. Capalinouniversity, Canada.

Welch, M. (2011). The evolution of the employee engagement concept: communication implications. Corporate Communication: An International Journal. Emerald group publishing limited, UK.

Wellins, R. S., Bernthal, P., \& Phelps, M. (2011). Employee engagement: the key to realizing competitive advantage. Development dimensions international inc, USA.

Wildermuth, C. M. S., \& Pauken, P. D. (2008). A perfect match: decoding employee engagement - Part 1: engaging cultures and leaders. Industrial and Commercial Training Journal. Emerald group publishing limited, USA.

Yu, H. C., \& Miller, P. (2005). Leadership style - The X Generation and Baby Boomers compared in different cultural contexts. Leadership and Organization Development Journal. Southern cross university, Australia.

Zhang, T. (2011). The relationship between perceived leadership styles and employee engagement: the moderating role of employee characteristics. Retrieved from http://www.researchonline.mq.edu.au/vital/access/manager/Repository/mq:14494

Zigarmi, D., Nimon, K., Houson, D., Witt, D., \& Diehl, J. (2009). From engagement to work passion: a deeper understanding of the work passion framework. Retrieved from http://www.kenblanchard.com/img/pub/Blanchard_From_Engagement_to_Work_Passion.pdf 